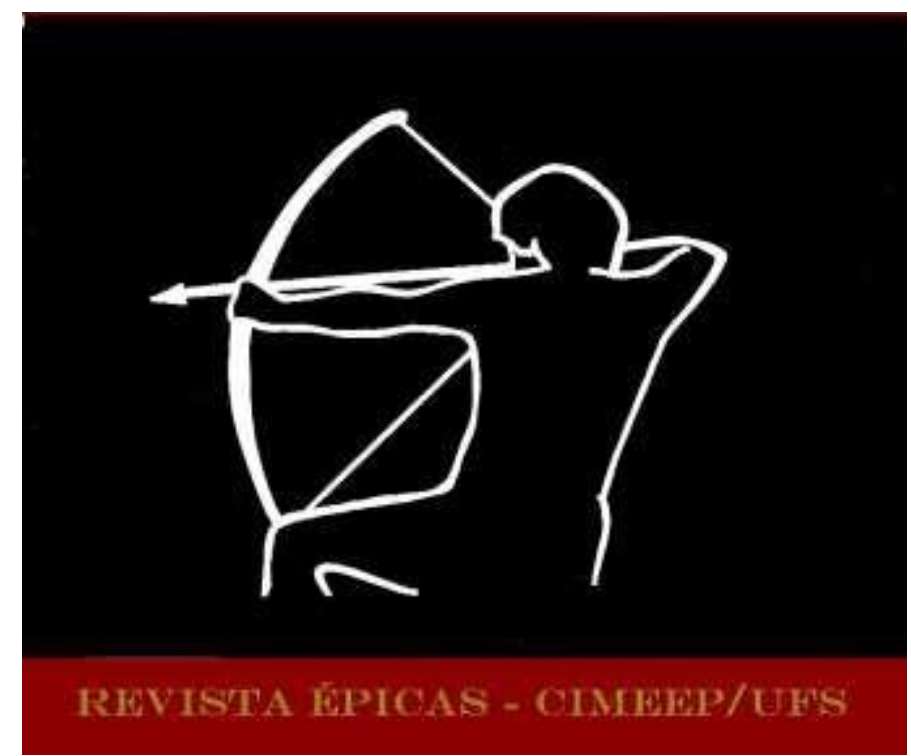

LANGENBRUCH, Beate. "Os doze pares de França vêm de Belém do Pará....": heranças e mutações do épico medieval francês na cultura popular brasileira. Trad. Antonio Marcos dos Santos Trindade. In: Revista Épicas. Ano 5, N. 10, Dez 21, p. 133-151. ISSN 2527-080-X, DOI: http://dx.doi.org/10.47044/2527-080X.2021v10.133151

\title{
"OS DOZE PARES DE FRANÇA VÊM DE BELÉM DO PARÁ ...": HERANÇAS E MUTAÇÕES DO ÉPICO MEDIEVAL FRANCÊS NA CULTURA POPULAR BRASILEIRA ${ }^{1}$
}

\author{
"THE TWELVE PAIRS FROM FRANCE COME FROM BELÉM DO PARÁ...": INHERITANCE AND MUTATIONS OF \\ THE FRENCH MEDIEVAL EPIC IN BRAZILIAN POPULAR CULTURE
}

Beate Langenbruch

ENS de Lyon, CIHAM (UMR 5648)

\begin{abstract}
RESUMO: Este trabalho analisa as múltiplas formas pelas quais a cultura popular brasileira atualiza a herança épica medieval francesa. Ao chegar ao Novo Mundo através da História do Imperador Carlos Magno, a matéria carolíngia faz sucesso com todos os públicos. As vozes individuais e coletivas são prova disso: a oposição pagão-cristã estruturante permanece operante e significativa até hoje em conflitos políticos, eventos culturais, folclore afro-brasileiro, literatura de cordel e música popular. E se Carlos Magno e seus Doze Pares fossem de fato brasileiros?

Palavras-chave: Matéria carolíngia, Recepção da herança épica medieval francesa no Brasil.
\end{abstract}

ABSTRACT: This work analyzes the multiple ways in which Brazilian popular culture updates the French medieval epic heritage. Arriving in the New World through the History of Emperor Charlemagne, the Carolingian material is a hit with all audiences. Individual and collective voices are proof of this: the structuring pagan-Christian opposition remains operative and significant to this day in political conflicts, cultural events, Afro-Brazilian folklore, cordel literature and popular music. What if Charlemagne and his Twelve Pairs were finally Brazilians?

Keywords: Carolingian material, Reception of the French medieval epic heritage in Brazil.

\footnotetext{
${ }^{1}$ Referência do artigo original: Beate Langenbruch, «"Les Douze Pairs de France viennent de Belém au Pará..." : héritages et mutations de l'épique médiéval français dans la culture populaire brésilienne», Le Recueil Ouvert [En ligne], mis à jour le : 10/11/2019, URL : http://ouvroir-litt-arts.univ-grenoble-alpes.fr/revues/projet-epopee/330--les-douze-pairs-de-france-viennent-de-belem-au-paraheritages-et-mutations-de-l-epique-medieval-francais-dans-la-culture-populaire-bresilienne. Tradução para o português do Prof. Dr. Antonio Marcos dos Santos Trindade (UFS).
} 
Os Doze Pares de França

Vêm de Belém do Pará...

Toquinho

Os Doze Pares de França viriam direto da floresta amazônica? É o que diz o compositor Toquinho na música "Os Doze Pares de França", gravada no disco de 1978, Toquinho Cantando - Pequeno Perfil de um Cidadão Comum. Se essa visão pode surpreender até mesmo especialistas de outros gêneros medievais, os conhecedores da epopeia romana, contudo, há várias décadas sabem da sobrevivência dos temas e personagens das canções de gesta na América Latina. Entre os muitos gêneros e formas de cultura erudita e popular que absorveram e transformaram a herança épica europeia, o cordel brasileiro é talvez o mais eminente, e a ele foram consagradas obras críticas importantes, nem sempre acessíveis em francês².

É também amplamente conhecido o caminho que vai da canção de gesta Ferrabrás (século XII) aos textos de cordel de temática carolíngia. Vamos relembrá-lo de forma bastante sucinta: A versão de Jehan Bagnyon, tabelião de Lausanne, uma das versões posteriores de Ferrabrás em prosa (entre 1470 e 1478), traduzida para o espanhol por Nicolas de Piemonte (1521), constitui o hipotexto da História do Imperador Carlos Magno composta em português por Gerônimo Moreira de Carvalho (1728), posteriormente ampliado por este autor, depois por outro, Alexandre Gaetano Gomes Flaviense, reduzido várias vezes depois, e reimpresso tanto em Portugal quanto em sua grande e longínqua colônia ultramarina ${ }^{3}$.

É, pois, essencialmente essa História do Imperador Carlos Magno, a qual teria viajado na bagagem dos colonizadores ${ }^{4}$, a célula matriz das manifestações brasileiras, provavelmente já na versão espanhola de Piemonte. Publicada pela primeira vez em Sevilha em 1521 pelo alemão Jacob Cromberger, cujas tipografias circularam pelo Novo Mundo, essa versão também entrou no mercado português. As impressões dos séculos seguintes, tanto a de Lisboa (1615) quanto a de Coimbra (1732), são outros canais de difusão: a História do Imperador Carlo Magno e dos Doze Pares de França... ${ }^{5}$, desse modo, pode ter atravessado o Atlântico, partindo de ambos os lados da Península Ibérica, antes mesmo de ter sido traduzida para o português.

\footnotetext{
2 Para uma primeira orientação sobre o cordel carolíngio em particular, podemos consultar os trabalhos pioneiros de Ferreira, Jerusa Pires, Cavalaria em cordel. O passo das aguas mortas [1993], São Paulo, Edusp, 2016; a seguir: Correia, João David Pinto, "O épico medieval nas tradições folclóricas portuguesas e brasileiras", in Bianciotto, Gabriel; Galderisi, Claudio (ed.), L'Épopée romane. Atas do XV Congresso Internacional Roncesvales, Poitiers, 21-27 de agosto de 2000, Poitiers, Universidade de Poitiers, CESCM, 2002, t. 1, pág. 15-29; Borges, Francisca Neuma Fechine, "Tradição e contemporaneidade no ciclo carolíngio da literatura de cordel brasileira", ibid., T. 1., p. 87-95; Cantel, Raymond, "De Roland a Lampião ou a literatura popular do nordeste brasileiro", Estudos de Literaturas Orais, Paris, 1979, p. 27-63, republicado em Cantel, Raymond, Literatura Popular Brasileira, nova edição expandida, Poitiers, Centro de Pesquisa da América Latina, 2005, p. 47-84. Sobre o cordel de maneira mais geral, ver Slater, Candice, Stories on a string: The Brazilian Literatura de Cordel, Berkeley, University of California Press, 1982; Meyer, Marlyse, Caminhos do imaginário no Brasil, São Paulo, Edusp, 1993; Santos, Idelette Muzart Fonseca dos, Literatura de Cordel no Brasil: memória de vozes, sótão das histórias, Paris, L'Harmattan, 1997 (Pesquisas e documentos da América Latina). Destacamos também as teses atuais de Bastos, Raïsa França, Movência da lenda carolíngia até o século XX brasileiro: estudo de uma transferência cultural, sob a direção de Idelette Muzart Fonseca dos Santos e Camille Dumoulié, em Paris Ouest Nanterre.

${ }^{3}$ Ver Cascudo, Luís da Câmara, "Informação sobre a História do Imperador Carlos Magno e dos Doze Pares de França", in Cinco livros do povo, João Pessoa, Editora Universitária, UFPB, 2 éd., 1979, p. 439-445, e Correia, João David Pinto, “O épico medieval...", op. cit., em particular p. 20-24.

${ }^{4}$ Ver Meyer, Marlyse, “Tem Mouro na Costa ou Carlos Magno 'Reis' do Congo”, in Caminhos do imaginário no Brasil, op. cit., p. 149, que se refere a Leonard, Irving, Los Libros del Conquistador, México, Fondo de Cultura, 1953.

${ }^{5}$ Ver Cascudo, Luís da Câmara, "Informação sobre a História do Imperador Carlos Magno e dos Doze Pares de França”, op. cit., p. 444 segs.
} 
Ferrabrás, a canção de gesta inicial, que entrou em novos domínios linguísticos pelos seus herdeiros diretos ou indiretos entre a Idade Média e o início do século XVIII, é talvez o texto épico medieval que conheceu a maior difusão geográfica e cultural ${ }^{6}$. Sua matéria se globalizou verdadeiramente, irradiando de forma épica ou dramática (via o Auto da Floripes, em particular) por todo o globo: originária da Europa, ela criou tradições longevas na América do Norte e do Sul, bem como na África7; além disso, eventos culturais recentes espalharam-na até a Ásia ${ }^{8}$. As inúmeras captações de espetáculos a fazem circular atualmente nos canais de difusão online, sem qualquer limitação geográfica.

Após ter estudado recentemente a travessia de fronteiras linguísticas e culturais a partir dessa matéria ${ }^{9}$, bem como certas questões de tradução implicadas em seu movimento de vaivém entre a França e o outro lado do Atlântico ${ }^{10}$ e por fim a imagem de Carlos Magno na literatura de cordel ${ }^{11}$, atualmente nos dedicamos a seus ecos épicos em diversas manifestações da cultura popular brasileira: manifestações essas tanto lúdicas quanto políticas, dramáticas, literárias e musicais. Como o grupo que diz Nós nessas representações modernas se apropriou a matéria europeia muito antiga, reinvestindo a herança medieval com nova criatividade e renovando seu ponto de vista, sua ideologia e suas ambições originais? Primeiramente vamos refletir sobre como essa matéria épica europeia, já bastante híbrida em sua chegada, pôde ser recebida por aqueles que vivem no Novo Mundo. Assim, dois tipos de atualização da matéria carolíngia no Brasil serão de nosso interesse: a primeira é a coletiva, ou seja, as manifestações sociopolíticas e socioculturais (a Guerra do Contestado, as congadas e as cavalhadas) e a outra a individual, ocorrendo tanto no cordel quanto num exemplo de lirismo musical.

\section{Um épico mestiço? Hipóteses sobre a recepção da matéria medieval no Brasil}

Quando se pensa nos vários herdeiros que o épico medieval Ferrabrás produziu no Brasil, fica-se tentado a aplicar-Ihes o rótulo de épico mestiço ${ }^{12}$, de acordo com os estereótipos atribuídos a esse país de misturas indiscutíveis, tanto a das populações indígenas com os que vieram e ainda vêm de todas as partes

\footnotetext{
${ }^{6}$ Ver Irradiação de Ferrabrás na literatura europeia, Atas do Colóquio Internacional de 6 e 7 de dezembro de 2002, dir. Marc Le Person, Lyon, APRIME, “C.E.D.I.C, 21", 2003.

7 Ver Mandach, André de, Nascimento e desenvolvimento da canção de gesta na Europa, V. A Gesta de Ferrabrás. O jogo do real e do improvável, Genebra, Droz, 1987 (Publicações românicas e francesas CLXXVII), p. 178-184. A tese de doutoramento de Alexandra Gouvêa Dumas, defendida em 2011 em Nanterre, coorientada por Armindo Jorge de Carvalho Bião (UFBA), Idelette Muzart Fonseca dos Santos (Paris Ouest Nanterre La Défense) apresenta um estudo comparativo de duas tradições dramáticas carolíngias, o Auto da Floripes no Príncipe, São Tomé e Príncipe, e a Luta dos Mouros e Cristãos no Prado, Bahia, Brasil: https://bdr.parisnanterre.fr/theses/internet/2011PA100221-1.pdf [consultado a 10/16 / 2019].

${ }^{8}$ O 19 Festival da Lusofonia em Macau em 2016 transmitiu a tradição do Auto da Floripes de Príncipe, existem algumas gravações online interessantes, mas de qualidade bastante mediana, ver https://www.youtube.com/watch? $V=$ f9mbgFFpEHE [acesso 16/10/2019].

${ }^{9}$ Langenbruch, Beate, "A Fronteira: desafio e riqueza para a investigação do épico medieval”, in: Lodén, Sofia; Obry, Vanessa (ed.), $A$ experiência das fronteiras e as literaturas da Europa medieval, Paris, Champion, 2019 (CCCMA , 26), p. 153-174.

10 Langenbruch, Beate, "Peregrinações transeuropeias e transatlânticas da matéria épica medieval: questões de tradução, entre a França e o Brasil", in Lautel-Ribstein, Florença; Buhot de Launay, Marc-André (ed.), Arqueologias da tradução, Paris, Classiques Garnier (Translatio), 2020, p. 195-213.

11 Langenbruch, Beate, "Carlos Magno, o Brasileiro: a figura do imperador construída pelo cordel do Nordeste", in: Kullmann, Dorothea, Oltre la mer salee. XXI Congresso Internacional da Sociedade Roncesvales, 13 a 17 de agosto de 2018, Toronto, Pontifício Instituto de Estudos Medievais, a ser lançado em 2022.

12 É por exemplo a abordagem de Kunz, Martine, “Cordel, criaçon mestiça”, in: Cultura critica, n 6 (2008), p. 26-32.
} 
do mundo quanto, claro está, com as diferentes culturas que lhe pertencem ${ }^{13}$. Todavia, além do fato de que conscientemente ou inconscientemente a própria ideia de cruzamento às vezes permanece articulada com uma perspectiva eurocêntrica, o livro de Serge Gruzinski, O pensamento mestiço, destacou todas as lacunas que essa palavra, "mestiço", pode implicar: como se existissem seres, comunidades ou culturas "puras" em si mesmas, como se a identidade fosse um fato único e não plural ${ }^{14}$. $\mathrm{O}$ caso concreto da canção de gesta Ferrabrás é um excelente exemplo disso: tendo viajado de uma língua a outra e cruzado uma série de fronteiras antes de chegar ao Brasil, a matéria medieval já chega ao país intrinsecamente misturada nos confrontos culturais pelos quais passou, sendo enriquecida em seu percurso histórico por vários cotextos, tanto os medievais (como a Crônica do Pseudo-Turpin ou o Speculum historiale de Vincent de Beauvais) quanto os renascentistas (a epopeia italiana), eruditos ou populares (como os folhetos ibéricos), até formar a História do Imperador Carlos Magno em suas múltiplas versões ${ }^{15}$. De modo que necessário se faz lidar com o conceito de cruzamento literário e cultural com cautela e precisão, sem abandoná-lo completamente por tudo isso, porém prestando atenção especial às áreas importantes de incerteza, aleatoriedade e às vezes esquivas - características-chave do cruzamento para S. Gruzinski, o qual, para descrever essa noção a partir dessas características, constrói seu "modelo de nuvem"16.

De fato, a matéria de Ferrabrás é uma contribuição europeia, de origem e essência medievais, portanto exógena, qualquer que seja a sua própria heterogeneidade, a qual vai ao encontro do Novo Mundo. Como imaginar sua recepção nesse novo território e por um público diferente? Para dizer a verdade, mesmo para os colonizadores, os quai são os mediadores da conquista que representa para o Brasil a apropriação da História do Imperador Carlos Magno (e realmente é uma conquista), a leitura do texto nessas novas latitudes, entretanto, torna-se diferente daquela que era realizada no horizonte cultural do qual ele proveio. Porém não foi o texto que mudou, ao fazer a travessia do Atlântico de barco, mas sim seus leitores e a perspectiva com que esses o leram. Afinal, o que encontram aí agora os portugueses e os espanhóis da Velha Europa? A uma provável nostalgia e emoção dos expatriados que leem a História como elemento de seu patrimônio individual e coletivo podem-se acrescentar, aos dados do terreno e à situação de acolhimento, efeitos de leitura particulares criados pela sobreposição ao cronotopo original. Certamente os conquistadores ou colonizadores não deixarão de atualizar em seu imaginário o texto que veiculam, levando em consideração a epopeia de conquistas militares, comerciais e culturais que eles próprios viveram e sobretudo não deixarão de reconfigurá-lo mentalmente, a partir dessa perspectiva. Nas guerras de Carlos Magno contra o Outro

\footnotetext{
${ }^{13}$ Saillant, Francine e Araujo, Ana Lucia, "A escravidão no Brasil: a obra do movimento negro", Etnologia francesa, vol. 37, $\mathrm{n}^{\circ} 3$ (2007), p. 457-466, relativizam a realidade do "mito da democracia racial", do qual o sociólogo brasileiro Gilberto Freyre foi um dos promotores: "Esse mito supõe uma visão harmoniosa da vivência das relações sociais e inter-raciais, entendendo-se que a 'raça' assume um significado mais cultural do que biológico aqui. Trata-se de uma incorporação fagocitária da diversidade de contribuições históricas e culturais de diversas populações à sociedade brasileira, em benefício de uma identidade única." (p. 457).

14 Ver Gruzinski, Serge, O pensamento mestiço, Paris, Arthème Fayard, 2012 (Plural), cap. II, "Misturas e cruzamentos", p. 33-57.

${ }^{15}$ Ver Cascudo, Luís da Câmara, "Informação sobre a História do Imperador Carlos Magno e dos Doze Pares de França", op. cit., e Correia, João David Pinto, “O épico medieval...”, op. cit., em particular p. 20-24.

${ }^{16}$ Ver Gruzinski, Serge, $O$ pensamento mestiço, op. cit., p. 55 segs.
} 
sarraceno, o almirante Balão e seus pagãos na Itália, França, Espanha e Terra Santa, um universo carolíngio fantasiado no contexto medieval das Cruzadas e da Reconquista, concretamente se sobrepõem outros confrontos militares sangrentos, trocas comerciais ou outros contatos entre cristãos da Europa e populações indígenas ou africanas reduzidas à escravidão e, claro está, mestiças, contatos de vários tipos que ocorrem principalmente nos sertões do Nordeste e da Amazônia.

Desse modo, o maniqueísmo épico apresentado pela História do Imperador Carlos Magno pode ser facilmente reinvestido, todavia esse reinvestimento se dá sem dúvida de forma ambivalente. Em um primeiro momento, a trama permite aos colonizadores se identificarem com os cristãos do texto e projetar esquematicamente nos pagãos do Novo Mundo os contornos da épica sarracena, ao rejeitá-los em uma alteridade global que a Idade Média não teria negado - quando todos os oponentes não cristãos de Carlos Magno, fossem eles saxões, eslavos ou sarracenos, podiam ser categorizados por uma denominação de pagão, sarraceno ou turco. Contudo, nesse Novo Mundo da Conquista, os imaginários antigos, indianos ou europeus, são perturbados, como Serge Gruzinski observa em relação ao México:

\begin{abstract}
Quanto aos conquistadores, logo perceberam que os vencidos não eram nem judeus nem muçulmanos e que a realidade que estavam descobrindo era mais confusa do que haviam imaginado à primeira vista. Se no início as imagens tiradas dos romances de cavalaria Ihes serviram para interpretar o que eles próprios não sabiam explicar, pouco ajudaram quando tiveram que se preparar para governar essa terra estranha e diabólica ${ }^{17}$.
\end{abstract}

Se a experiência descrita parece transportável em seus traços principais para o Brasil do século XVI, também é importante valorizar seu contexto específico. A conquista do Brasil, não menos assassina, nem menos brutal para os índios ou escravos da África do que as conquistas do México ou do Peru, teria, porém, se caracterizado por uma notável lentidão e ineficiência administrativa, devido à "fragilidade da presença portuguesa", que também deixou "maior margem de manobra para grupos de interesse e indivíduos fixados nessa nova terra". Não obstante, estes últimos são "em parte degradados, isto é, delinquentes portugueses condenados ao exílio através do Atlântico, em parte aventureiros europeus", elétrons livres cujas inclinações estariam na origem de mais numerosos cruzamentos no Brasil do que em outros lugares: "Mais do que nos Andes e mais do que no México, as fronteiras entre as populações - europeus, mestiços, índios convertidos, índios da floresta - estão em movimento e são confusas" ${ }^{18}$.

Que significado isso tem para a leitura, ou melhor, para as possíveis leituras históricas de nosso texto? Sem poder reconstruir atualmente de forma exata a recepção da História do Imperador Carlos Magno no Brasil por esses diferentes grupos - heterogêneos como são - e de século em século, por falta de fontes específicas, seu sucesso testemunha um interesse amplamente compartilhado. A matéria épica medieval,

17 Ibid., p. 72.

$18 \mathrm{Ibid} .$, p. 76, para esse parágrafo e todas as citações. 
uma "história de grandeza" ${ }^{19}$, permite que qualquer pessoa que queira estabelecer uma filiação real ou imaginária com ancestrais distantes, cujos sonhados prestígio e antiguidade remontam a Carlos Magno, possa se identificar com ele.

No entanto, será que podemos imaginar uma identificação positiva, da parte das populações colonizadas e escravizadas, com essa herança literária de invasores e opressores assassinos? Embora pareça surpreendente, nada impede que se pense assim, muito pelo contrário. Em todo caso, sabemos que, mais tarde no século XIX, a História de Carlos Magno impôs-se em quase todos os lares nordestinos, onde muitas vezes é o único livro ${ }^{20}$. Os grandes escritores brasileiros Oswald de Andrade, João Guimarães Rosa, Graciliano Ramos, Cyro dos Anjos ou Monteiro Lobato fazem empréstimos explícitos de sua matéria em suas obras; o filósofo João Cruz Costa lembra-se de ter ouvido, em criança, o cozinheiro negro de sua casa contar histórias de Carlos Magno; ainda hoje, com ou sem razão ${ }^{21}$, intelectuais e líderes de todos os matizes políticos referemse a ela ${ }^{22}$, tomando como modelo o imperador franco. De maneira que todos os grupos sociais, letrados ou não, têm acesso, de uma forma ou de outra, à matéria épica medieval, muitas vezes considerando-a como uma leitura fundamental e um pilar do patrimônio cultural nordestino, se não brasileiro.

Por ser um vetor do cristianismo no Novo Mundo, a História do Imperador Carlos Magno (e antes dela, a espanhola História del Emperador Carlomagno) pode de fato oferecer atrações aos convertidos da Conquista, ao ser utilizada aí como instrumento de doutrinação religiosa ${ }^{23}$. Muitos e prestigiosos são os seus exemplos de conversão: o batismo do rei Clóvis por São Remígio (Livro I, cap. $4^{24}$ ) por instigação de sua esposa Clotilde, a vitória honrosa de Oliveiros na luta contra Ferrabrás, seguida da conversão deste ao cristianismo (Livro II, cap. XVI), a ascensão da bela pagã Floripes, batizada e então casada com Gui de Borgonha (Livro II, cap. XLVI). Mulheres e homens são assim convidados, se não estimulados, a se identificarem com os heróis de um livro popular, seduzidos por um colonizador que, manu militari, também se torna social e culturalmente dominante. O papel das relíquias desempenhado no texto, em particular o de São Bálsamo, também é importante: os milagres produzidos (como no livro II, cap. XLVII) conferem uma aura mágica a

\footnotetext{
${ }^{19}$ Kunz, Martine, "Cordel, criaçon mestiça”, op. cit., p. 26.

${ }^{20}$ Ver Cascudo, Luís da Câmara, "Informação sobre a História do Imperador Carlos Magno e dos Doze Pares de França”, op. cit., p. 441.

${ }^{21}$ Meyer, Marlyse, "Tem Mouro na Costa ou Carlos Magno 'Reis' do Congo", op. cit.

22 Ver entrevista do efêmero Presidente da República Michel Temer ao jornal conservador O Globo em setembro de 2016 https://oglobo.globo.com/brasil/me-sinto-como-carlos-magno-diz-presidente-michel -temer -20087374, [consultado em 17/10/2019], e as reações controversas às suas reivindicações, https://oglobo.globo.com/brasil/temer-reconhece-que-se-confundiuao-relacionar-carlos-magno-tavola -redonda-20091911 [consultado em 17/10/2019].

${ }^{23}$ Ver Montero, Luis Humberto Olera, "La 'Historia de Carlo Magno' en el desarrollo del romancero a la décima espinela", Revista Chilena de Literatura, $\mathrm{n}{ }^{\circ} 78$ (2011), online: https://web.archive.org / web / 20131231074431 / http: //revistaliteratura.uchile.cl/index.php/RCL/article/viewArticle/11021/11437 [acesso em 16/10/2019].

${ }^{24}$ Referimo-nos à versão aumentada do texto de Alexandre Gaetano Gomes Flaviense, História do imperador Carlos Magno e dos doze paros de França, traduzida do castelhano, por Jeronymo Moreira de Carvalho... e seguida de Bernardo del Carpio que venceu em batalha aos pares de França, Rio de Janeiro / Paris/Lisboa, Garnier, 1892, disponível em Gallica, https://gallica.bnf.fr/ark: /12148/bpt6k11648284/f5. image [consultado em 16/10/2019], além da versão em espanhol de 1780, também online: http://bibliotecavirtualdefensa.es/BVMDefensa/i18n/consulta/registro.cmd?id=1641 [acesso em 16/10/ 2019].
} 
esses heróis literários convertidos, por meio de ou para o benefício de quem as manifestações transcendentes precisamente ocorrem.

A História do Imperador Carlos Magno, conhecida na América já em 1536, apenas quinze anos após sua primeira edição em Sevilha, é apreciada individualmente no outro lado do Atlântico, mas também, e talvez acima de tudo, em leituras coletivas em voz alta ${ }^{25}$. É o fascínio exercido pela matéria épica medieval, a qual sem dúvida oferece um sonho de grandeza em tempos de crise aguda, qualquer que seja o campo de onde se venha, o que incontestavelmente é comum aos diferentes grupos de leitores ultramarinos desses herdeiros da canção de gesta Ferrabrás em espanhol e português. A História de Carlos Magno, vindo de uma grande e antiga matéria e encontrando uma nova legitimidade e reconhecimento no Novo Mundo, pode atualizar-se no hemisfério sul com razão como uma epopeia: um texto que permite a todos os seus leitores uma saída honrosa de uma realidade em crise ${ }^{26}$, a saber: a da conquista militar, espiritual, econômica e cultural. É bem possível que seja justamente a constante instabilidade desse novo contexto a responsável em parte pelo sucesso do texto no Brasil, talvez se tornando, assim como seu predecessor, a Canção de Rolando, um "instrumento de pensamento político", de acordo com a formulação de Florence Goyet ${ }^{27}$. Como oferece, além disso, um relato bom, simples e fascinante dos feitos de armas e do heroísmo, uma parte dos ouvintes-leitores também pode ser conquistada adotando-se o prisma cristão que ele propõe, sem fazer outras perguntas além do prazer do texto.

É claro que obviamente pode haver rejeição total da matéria: entre leitores que se recusam a entrar em contato com qualquer manifestação cultural ligada aos colonizadores ou, simetricamente, por aqueles que, apesar de pertencerem ao grupo dominante, relutam em aceitar a ideia de conversão na ponta da espada, bem como qualquer texto que pudesse legitimar e representar

[...] a ordem unitária que se pretendeu implantar a ferro e fogo no Novo Mundo: uma fé, uma lei, um rei. O conjunto Carlos Magno-Doze Pares serviu no Brasil para dizer contradições da História, nostalgias, visões de mundo, pelo que também veicula, numa representação simbólica da rede de relações que se estabelece e se reproduz na terra colonial, a marca dessas relações: a violência ${ }^{28}$.

Resta saber que a diversidade e o número de testemunhos recolhidos pela crítica atestam a amplitude da recepção que teve a História do Imperador Carlos Magno.

\footnotetext{
${ }^{25}$ Ver Montero, Luis Humberto Olera, "La 'Historia de Carlo Magno' en el desarrollo del romancero a la décima espinela”, op. cit., que se refere a Saavedra, Yolando Pino, "La Historia de Carlomagno e de los Doce Pares de Francia en Chile", in: Folklore Américas, n - 26 (1966), p. 1-29, para o primeiro testemunho americano e para o envio de 10 cópias da História para as Américas em 1586.

${ }^{26}$ Ver Goyet, Florence, Pensar sem conceitos: a função da epopeia guerreira, Paris, Champion, 2006, p. 557: "[...] A epopeia é um texto que resolve uma crise política contemporânea, de outra forma insolúvel, ao confrontar valores conflitantes em personagens que ela constrói para esse fim. Isso permite que o público veja esses valores 'em jogo', tendo-os em mira, e lhes dá um controle intelectual sobre o presente caótico.".

27 Ibid., p. 349.

${ }^{28}$ Meyer, Marlyse, “Tem Mouro na Costa ou Carlos Magno 'Reis' do Congo", op. cit., p. 156. Salvo indicação em contrário, todas a s traduções nesse trabalho são nossas.
} 
Como essa matéria épica de origem europeia é reinvestida por brasileiros de todos os segmentos sociais? O que são as recreações épicas, lúdicas e dramáticas ou musicais produzidas pelos círculos populares, quais são as apropriações políticas, espirituais e artísticas da matéria e como se articula a oposição entre a Nossa perspectiva e a dos Outros?

\section{Reinvestimento político e folclórico da matéria carolíngia no Brasil: o movimento do Contestado, as congadas e as cavalhadas}

As reutilizações do material épico veiculado pela História de Carlos Magno são inúmeras no Brasil. Elas eram também favorecidas por outros possíveis intertextos carolíngios ${ }^{29}$, muitas vezes marcados por uma verdadeira mistura cultural. Abordaremos aqui as manifestações da cultura popular que são capazes de testemunhar em grande medida a forma como um grupo se apodera das relações entre Nós/cristãos com os Outros/pagãos que the legou a herança épica medieval. Os três exemplos estudados, o movimento do Contestado, as congadas e as cavalhadas, ilustram em particular a forma como se atualiza o grupo formado por Carlos Magno e os Doze Pares, e pela qual o maniqueísmo épico se preserva em novos contextos sociais e históricos.

Ao criar as canções de gesta na virada dos séculos XI e XII, a Idade Média francesa se reapropriou da figura histórica e mítica do imperador franco, embora ele já estivesse morto há três séculos: no processo secular que é a etnogênese francesa ${ }^{30}$, a aura que o envolve e a carga simbólica que ele representa ainda são úteis para a sociedade que produz esses textos de um novo gênero literário. De forma semelhante, o movimento messiânico e social do Contestado no Brasil (1912-1916) se reconecta com a matéria carolíngia. As reivindicações dessa rebelião contra o jovem Estado brasileiro do Sul, nas fronteiras do Paraná, Santa Catarina e Argentina, dizem respeito à defesa de pequenos fazendeiros e camponeses expropriados, muitos dos quais são caboclos, mestiços euro-índios. Em 1912, à época do carismático líder José Maria de Agostinho, o conflito se transformou em guerra. José Maria de Agostinho, por sua vez, havia sucedido a dois ilustres antecessores, os quais eram monges, adotavam cada um o nome de João Maria ${ }^{31}$ e deram origem a um grande movimento messiânico. José Maria, (falso?) monge, curandeiro e "messias caboclo" ${ }^{32}$, inspira as multidões ao tingir o conflito com uma semiótica erudita da guerra santa, na qual está integrada a herança épica medieval:

\footnotetext{
${ }^{29}$ Queremos aqui abordar apenas as formas de reajustamento especificamente brasileiras: o Auto da Floripes, por exemplo, ou os romanceiros já conhecidos e lidos na Península Ibérica, os quais, contudo, não fazem parte das nossas reflexões, embora possam também promover o conhecimento da matéria carolíngia no Brasil, ao lado da HCM.

${ }^{30}$ Ver Langenbruch, Beate, Imagens da Alemanha em algumas canções de gesta dos séculos XII e XIII, tese de doutorado defendida na Universidade de Rouen, Orient. Jean Maurice, 2007.

${ }^{31}$ Queiroz, Maurício Vinhas de, Messianismo e conflito social (A Guerra sertaneja do Contestado 1912-1916), São Paulo, Ática, 1981 (Ensaios, 23), cap. II, “O Profeta João Maria: Realidade e mito", p. 49-63.

32 Ibid., Cap. IV, “José Maria, o Messias caboclo”, p. 77-101.
} 
[...] Para si mesmo e para seus discípulos leu a História de Carlos Magno e dos Doze Pares de França. No primeiro encontro que ele organiza, o de Taquaruçu, há atividades devocionais diárias. Oração e leitura pública da História de Carlos Magno. Mas também há a organização dos primeiros Pares da França ${ }^{33}$.

A eficácia da atualização da matéria carolíngia repousa no binarismo épico, que rejeita o Estado federal enquanto alteridade, ao demonizá-lo explicitamente. Por outro lado, na ocasião do conflito armado de Caraguatá ${ }^{4}$, depois de um conselho deliberativo e multiplicador de anúncios do mesmo nome, formado durante a reunião de Taquaruçu ${ }^{35}$, esse grupo se assume como o campo cristão, ao designar um soberano, criar uma guarda de honra para ele composta de vinte e quatro cavaleiros, chamá-los de "Doze Pares da França" e armá-los com espadas de madeira ${ }^{36}$. Uma bandeira, uma cruz verde sobre o fundo branco ${ }^{37}$ no estilo dos estandartes das cruzadas medievais, representa a monarquia celeste de um novo tipo de movimento que aspira a estabelecer-se. A intensa frequência, tanto do hipotexto literário quanto de outras festividades folclóricas ${ }^{38}$, mantém facilmente essa atualização entre os rebeldes, ao criar um forte vínculo afetivo entre eles e os investir com o papel de novos cruzados.

O Brasil desenvolveu outras reapropriações da matéria épica medieval, em maior escala espaçotemporal: dessa vez, misturas do modelo carolíngio com as tradições africanas. A congada, considerada uma manifestação folclórica do sincretismo religioso, é um teatro de rua ou procissão afro-brasileira que combina música, canto, dança e elementos históricos ${ }^{39}$. Ela não é nordestina, porém, tendo suas altas posições nos estados mais meridionais de São Paulo, Espírito Santo, Goiás e Minas Gerais, nas regiões Sudeste/Centro, portanto. A congada celebra a coroação do Rei do Congo (Reis do Congo) e da sua Rainha, na qual intervém o Embaixador angolano como saqueador, aliás filho ilegítimo do soberano do Congo, a quem ele provoca militarmente em várias ocasiões, antes de ser perdoado e reconhecido. Esse é apenas um exemplo de um esboço bastante básico para um espetáculo total, cujo enredo e produção precisos variam de local para local. Alguns municípios, como o de Ilhabela, estão trabalhando em um texto que foi fixado e até editado ${ }^{40}$, ao passo que em outros lugares grande parte do texto é deixada ao improviso.

\footnotetext{
${ }^{33}$ Monteiro, Duglas Teixeira, Os Errantes do Novo Século, São Paulo, Duas Cidades, 1974, p. 271, que citamos através de Meyer, Marlyse, “Tem Mouro na Costa ou Carlos Magno ‘Reis'do Congo", op. cit., p. 151.

${ }^{34}$ Ver Queiroz, Maurício Vinhas de, Messianismo e conflito social (A Guerra sertaneja do Contestado 1912-1916), op. cit., p. 319.

35 Ibid., p. 149.

36 Ibid., p. 125.

${ }^{37}$ Cf. ibid., "Atributos e funções dos pares de França", p. 184-186.

${ }^{38}$ Queiroz, ibid., p. 184, indica que, ao lado da HCM, as cavalhadas (que serão discutidas a seguir) também podem ter desempenhado um papel na criação dos pares de França.

39 Para introduções a essa manifestação popular, ver Meyer, Marlyse, "Neste Mês do Rosário: indagações sobre congos e congadas", op. cit., p. 161-169; Cirino, Giovanni, "Atuação missionária no Brasil e na África Centro-Ocidental: uma interpretação dos autos catequéticos", in Dawsey, John; Müller, Regina; Monteiro, Marianna; Hikiji, Rose Satiko (ed.), Antropologia e Performance, São Paulo, Terceiro Nome, 2013, p. 217-234; Filgueira de Almeida, Dulce, "Corpo, Cultura e Sincretismo: o Ritual da Congada", Pensar a Prática, vol. 15, no 1 (2012), p. 22-36; Cezar, Lilian Sagio, "A santa, o mar e o navio: congada e memórias da escravidão no Brasil”, Revista de Antropologia, vol 58, $\mathrm{n}^{\circ} 1$ (2015), p. 363-396; Bastide, Roger, As religiões africanas no Brasil. Contribuição para uma sociologia das interpenetrações da civilização. Paris, PUF, 1995 [1960], p. 479-483.

40 Ver o documentário em 6 episódios sobre essa congada, produzido pela TV USP, disponível online, https://www.youtube.com/watch? V = CpCuk441ZCw [acesso em 17/10/2019].
} 
Essas congadas geralmente acontecem no dia de um santo venerado pela comunidade negra, Nossa Senhora do Rosário ou São Benedito, ou em um feriado católico importante (como o Natal ou 6 de janeiro, festa dos Reis Magos). De fato, são as irmandades negras das freguesias que são portadoras e protagonistas dessa festa, cujas origens remontam, no mínimo, ao início do século XVIII ${ }^{41}$. Um elemento estruturante importante são os ternos (companhias ou batalhões): os participantes da festa, fantasiados, organizam-se em batalhões e marcham segundo uma hierarquia social estrita, precedendo ou seguindo o grupo central, nomeadamente o casal real e os seus grupos de elite, os $\operatorname{congos}^{42}$. A peculiaridade dessa festa está em sua estreita ligação com a violência bilateral:

A guerra é representada na forma de uma festa, enquanto na festa se apresenta um conteúdo de guerra. Contexto representado: guerra em forma de festa. Contexto da representação: festa com conteúdo de guerra ${ }^{43}$.

O maniqueísmo do espetáculo é alimentado pela oposição religiosa: o grupo de cristãos (os representantes do Congo) se opõe ao dos pagãos, associados aos moçambicanos ou angolanos. Em seu estudo da congada, Roger Bastide menciona que a oposição dos grupos nacionais africanos também se cruza com diferenças sociais notáveis: a aristocracia congolesa, desse modo, enfrenta o meio mais popular dos moçambicanos ${ }^{44}$. Podemos facilmente adivinhar por que o poeta Mário de Andrade, ao estudar a congada entre as "danças dramáticas" 45 , associa o "tema de Carlos Magno e dos Pares" a ela: a luta entre cristãos e mouros, em tantas regiões do Brasil (sobretudo no Nordeste) conhecida como um tema folclórico ou dramático estruturante (no Auto da Floripes), aí é reinvestida e fundida com danças e tradições africanas, cujas oposições históricas e sociais apresentam semelhanças. Além disso, às vezes o soberano carolíngio aparece pessoalmente no espetáculo e, ao seu lado, os pares. Na verdade, o tema carolíngio

[...] pode subsistir numa seqüência completa, como é a do cortejo e batalha singular entre Oliveiros e Ferrabrás, sob os olhos do majestoso Carlos Magno, belo mulato vestido de veludo azul celeste, desfilando na Congada de São Benedito em Poços de Caldas, sob a batuta de Zé do Brejo, a memória do texto ${ }^{46}$.

Na manifestação de Poços de Caldas em Minas Gerais, Carlos Magno e os Doze Pares de fato formam um congo, um batalhão ${ }^{47}$. Apoiando-se no testemunho da congada de llhabela, um crítico evoca também a proximidade fonética entre a espada Durendal, "espada durindana" em português, a qual, na canção de

\footnotetext{
${ }^{41}$ Ver Filgueira de Almeida, Dulce, “Corpo, Cultura e Sincretismo: o Ritual da Congada”, op. cit., p. 23.

42 Ver Meyer, Marlyse, "Neste Mês do Rosário: indagaçoes sobre congos e congadas", op. cit., p. 162.

${ }^{43}$ Cirino, Giovanni, "Atuação missionária no Brasil e na África Centro-Ocidental: uma interpretação dos autos catequéticos", op. cit., p. 226.

${ }^{44}$ Ver Bastide, Roger, As religiões africanas no Brasil. Contribuição para uma sociologia das interpenetrações da civilização, op. cit., p. 482.

${ }^{45}$ Cf. Andrade, Mário de, Danças dramaticas do Brasil, Belo Horizone, Itatiaia/INL/Fundação Pró-Memória, 1982, t. 1, pág. 102-104 e "Os Congos", Danças dramaticas do Brasil, Belo Horizone, Itatiaia/ INL/Fundação Pró-Memória, 1982, t. 2, pág. 17-48.

46 Meyer, Marlyse, "Tem Mouro na Costa ou Carlos Magno ‘Reis'do Congo", op. cit., p. 149.

47 Ver Meyer, Marlyse, “Neste Mês do Rosário: indagaçoes sobre congos e congadas”, op. cit., p. 162.
} 
gesta $^{48}$, Carlos Magno põe-se ao lado de Rolando durante a cerimônia de ordenação em que esse herói é consagrado cavaleiro, e a espada durumbamba ou zurumbamba que o Rei do Congo apresenta ao Embaixador em um momento crucial da intriga, na atuação dramática brasileira ${ }^{49}$. A semiótica de Nós/cristãos versus os Outros/pagãos é muito acentuada, conforme atestam as numerosas gravações de vídeo de congadas disponíveis na Internet. Trajes, cores e símbolos consagram essa oposição binária, facilmente identificável: aos cavaleiros cristãos em cor azul celeste, acompanhados das bandeiras dos santos padroeiros dos negros como São Benedito, Santa Ifigênia e Nossa Senhora do Rosário, enfrentam os batalhões pagãos vestidos de vermelho, alguns dos quais tem chapéus adornados com chifres diabólicos; às vezes um líder de um desses congos pode até ser chamado de Ferrabrás, como ocorre com o sarraceno na canção de gesta medieval, o qual foi derrotado por Oliveiros e depois se converteu ao cristianismo.

A origem da congada é obscura. Alguns acreditam que o plano dramático dela provenha de autos (jogos dramáticos) compostos por jesuítas ibéricos para fins catequéticos, possivelmente já na África, e que foi por meio dos escravos negros que esse folclore-de-encruzilhada chegou ao Brasil: essa hipótese é sedutora e possível, porém sem provas concretas ${ }^{50}$. Nem sempre apreciada, nem sempre autorizada pela Igreja nos séculos anteriores ${ }^{51}$, a congada é atualmente um elemento importante do folclore afro-brasileiro, mas não exclusivamente: os papéis de cristãos e mouros que nela são interpretados não se distribuem necessariamente de acordo com a suposta origem étnica dos atores e, por serem em grande medida manifestações populares, elas acabam acolhendo brasileiros de todas as origens ${ }^{52}$.

Enquanto a congada associa a veneração ritual ao riso numas passagens, realizando com dileção inversões burlescas, capotamentos das hierarquias sociais e do tema épico pelo meio da provocação, em resumo, mostrando seu caráter carnavalesco, outras manifestações folclóricas estão mais próximas da veneração séria, sem excluir totalmente o cômico. As cavalhadas, "cavalgadas", que assumem a oposição cristãos versus pagãos, são muito difundidas no país e utilizam os mesmos códigos de cores das manifestações anteriores ${ }^{53}$. Esses desfiles e confrontos a cavalo, os quais são flexíveis em relação ao lugar e à função, podem integrar uma congada como evento matinal ou podem ser festejados de forma independente, ao longo de vários dias. Desse modo, a cavalhada de Pirenópolis, no estado de Goiás, a qual se estende por três dias, vê, um após o outro, os elementos estruturantes da épica medieval: a luta entre os

\footnotetext{
48 Ver Suard, François (ed.), Aspremont. Canção de gesta do século XII, Paris, Champion, 2008 (Champion Classiques. Idade Média), que anuncia esse grande acontecimento na história desde o seu prólogo: “Or vos dirai d'Yaumont et d'Agoulant, / Et d'Aspremont ou li estors fu grant, / Si com li rois adouba Rollant / Et il li ceint a son costé le branc, / Ce dist la geste Durendart la trenchant, / C'est la première dont il onques fist sanc, / Dom il ocist le fil roi Agoulant." (Contarei a vocês sobre Eaumont, Agoulant e Aspremont em que passagens a batalha foi terrível; contarei como o rei cavaleiro Rolando cingiu a espada à cintura - era, disse a gesta, Durendal a boa. Afiada, aquela pela qual, pela primeira vez, ele derrama sangue, matando o filho do rei Agoulant.", traduzido por Franço is Suard). ${ }^{49}$ Ver Cirino, Giovanni, "Atuação missionária no Brasil e na África Centro-Ocidental: uma interpretação dos autos catequéticos", op. cit., p. 230.

${ }^{50} \mathrm{Cf}$. ibid., p. 229.

${ }^{51}$ Cf. Bastide, Roger, As religiões africanas no Brasil. Contribuição para uma sociologia das interpenetrações da civilização, op. cit., p. 482.

52 Cf. ibid., p. 479 seg.

${ }^{53}$ As fotos das cavalhadas de Pirenópolis, Goiás, oferecem belos vislumbres: https://pirenopolis.tur.br /cultura/folclore/festa-do-divino/cavalhadas [consultado em 17/10/2019].
} 
Doze Pares cristãos e os Doze Pares sarracenos (mouros); após isso, assiste-se à conversão dos mouros, antes que o júbilo popular atinja a culminância no último dia, em que há a representação de um torneio para o qual, em uma grande cavalgada de fantasias e danças ${ }^{54}$, acorre um número muito maior de participantes.

Esses três exemplos de reapropriação da matéria carolíngia ilustram seu reinvestimento coletivo: o de um agrupamento social e político em um determinado contexto histórico, depois em uma comunidade, em um bairro ou às vezes em uma cidade inteira, mobilizada em torno de um patrimônio folclórico ainda vivo atualmente. Concentraremos agora nosso olhar no fenômeno da enunciação individual, em duas outras expressões populares do épico de inspiração medieval no Brasil.

\section{As vozes discretas do cordel e da canção: poesia popular de inspiração carolíngia}

\subsection{Nós/cristãos e os Outros/pagãos no cordel}

A História de Carlos Magno não é a única narração que transmitiu matéria épica medieval. Já no final do século XIX, graças em particular ao poeta nordestino Leandro Gomes de Barros, nasceu um gênero que prometia enorme sucesso popular no Brasil, o cordel. Ao contrário da prosa, forma usada em folhetos do mesmo nome produzidos em Portugal, o cordel brasileiro é versificado; suas estrofes são regulares, compostas por seis (sextilha), sete (setilha) ou dez versos (décima). Leandro Gomes de Barros produziu mais de duzentos cordéis, incluindo dois textos inspirados na História de Carlos Magno, o díptico A Batalha de Oliveiros com Ferrabrás e A Prisão de Oliveiros e seus companheiros. Trata-se do duplo núcleo do cordel carolíngio, agrupamento livre de uma dezena de textos não ligados diretamente entre si e posteriormente compostos por diversos autores ${ }^{55}$, um todo que, portanto, carrega uma matéria épica medieval ativa até hoje.

As vozes dos autores, os quais, desejosos de entrar numa história fascinante para transmiti-la ao leitor, às vezes chamado de forma direta, são muitas vezes discretas no limiar dos primeiros cordéis carolíngios, os de Leandro Gomes de Barros, já mencionados, depois Roldão no Leão de Ouro, de João Melchíades Ferreira, ou O Cavaleiro Roldão, de Antonio Eugênio da Silva. Contudo, a maioria das histórias logo adquirem prólogos, alguns dos quais não têm nada a invejar das canções de gesta medievais: esse é o lugar onde a consciência autoral é mais claramente afirmada. Eles ilustram uma perspectiva que até então está apenas implícita: “Em geral, o poeta popular nordestino é católico ortodoxo." ${ }^{56}$. Essa perspectiva, mesmo que seja apenas um ethos do narrador, mantém-se globalmente válida mesmo entre os autores mais recentes, como Stélio Torquato Lima ou Marco Haurélio. Também a fronteira entre Nós/cristãos e os

\footnotetext{
54 Ver a apresentação da cavalhada de Pirenópolis no canal da Câmara dos Deputados no YouTube: https://www.youtube.com/watch? V = SJjL2CO_8h4 [acesso em 17/10/2019].

55 Os quais compõem o corpus com o qual estamos trabalhando atualmente.

56 Melo, Veríssimo de, "Literatura de Cordel. Visão histórica e aspectos principais ", in: Literatura de cordel. Antologia, Fortaleza, Banco do Nordeste do Brasil, 1994, p. 15.
} 
Outros/pagãos trazida pela matéria épica medieval é facilmente atualizada: é aquela que separa os cristãos, defensores da Igreja e do "Deus poderoso" (Malaco, p. 1), de traidores pérfidos como Ganelão / Galalão, "grande canalha" ( $A R$, p. 14), e de pagãos, "os inimigos/da religião cristã" (Malaco, p. 1), seguidores da "doutrina diabólica" (GBC, p. 31). Em O Guerreiro Bernardo de Cárpio. Exímio vencedor dos Doze Pares de França, de Severino Borges da Silva, essa doutrina parece incluir até os ritos mestiços:

\author{
Bernardo de Cárpio ${ }^{57}$, [sic] foi \\ O herói do mundo inteiro, \\ Reagiu lutas tremendas, \\ Guerrilhou o estrangeiro, \\ Estraçalhou os Magomas, \\ Símbolo catimbozeiro ${ }^{58}$. FIM.
}

O desejo explícito dos autores é dar exemplos de um heroísmo excepcional: a ambição épica está, pois, perfeitamente intacta nessa literatura popular, para a qual os Doze Pares continuam atualmente incomparáveis (cf. PO, p. 6) e, entre eles, Rolando e Oliveiros em particular (M12P, p. 2), seguido por Renaut de Montauban, o qual não encontra paralelo na Cristandade (Malaco, p. 40); até o "famoso" Imperador Carlos Magno (GPCM, p. 1) passa a fazer parte do rol dos heróis, embora, no cordel de Severino José, ele seja curiosamente um amante excepcional e não um guerreiro. Com certeza, para os leitores brasileiros modernos, susceptíveis de receber choques emocionais de tal forma que seus corações deixem de bater ("Nessa história, os leitores sentirão choques de parar o coração", GBC, p. 1), o valor exemplar dos heróis herdados da Idade Média europeia e sua "história/de grande admiração" (HCM, v. 4) não perderam o interesse. Mais precisamente, esses heróis, cujas vidas são contadas "pra ficar memoriada/no coração brasileiro" (GBC, p. 1), apresentam a tendência de ser vistos como verdadeiros emblemas nacionais. O longo epílogo da História de Carlos Magno insiste na relação entre a obra missionária de Carlos Magno, defensor da Igreja e devorador de pagãos (cf. HCM, p. 42), e o dever de reconhecimento e memória formulado por "nossa pátria brasileira" (ibid.), tal como se dá no ano de 1978 - o qual, a despeito da vontade do poeta, é a data de aniversário não da morte de Carlos Magno, mas da batalha de Roncesvales. Ainda que não se possa afirmar se "todos os brasileiros" (Ibid.) comemoraram piedosamente o 15 de agosto de 1978, apesar disso o texto de João Lopes Freire é um cordel de memória criado especificamente para essa ocasião:

\author{
Será lançado este livro \\ entregue de mão em mão \\ em memória de Carlos Magno \\ que lutou com devoção \\ defendendo a santa igreja \\ só devorando pagão. (Ibid.)
}

\footnotetext{
${ }^{57}$ N.T. A vírgula respeita a citação do texto original em francês.

$58 \mathrm{O}$ adjetivo catimbozeiro se refere à catimbó, a fumaça que incensa os presentes em um rito mágico que combina elementos indígenas, africanos e cristãos. Magomas é um termo mais complicado de traduzir: Magoma é, por um lado, uma língua africana falada na Tanzânia; o contexto, porém, parece referir-se a um objeto usado durante o culto e é provável que haja confusão com a macumba. Essa palavra designa um instrumento musical africano e por extensão os ritos afro-brasileiros e suas práticas; nessa segunda acepção, a palavra apresenta, conforme nossa compreensão, uma possível conotação depreciativa.
} 
A relação entre o catolicismo brasileiro e a matéria carolíngia não desempenha um papel de destaque no cordel mais recente, as Aventuras de Roldão. Marco Haurélio, como autor bem documentado e ciente das múltiplas camadas que compõem o seu hipotexto principal, a História do Imperador Carlos Magno de Jerônimo Moreira de Carvalho, está, por outro lado, muito apegado à dimensão patrimonial do modelo épico medieval, esse Rolando, "que inspirou, em outras épocas, os cowboys do Far West americano, os cangaceiros [partidários do banditismo revolucionário no Brasil] e os vaqueiros nordestinos" (AR, prefácio, p. 2):

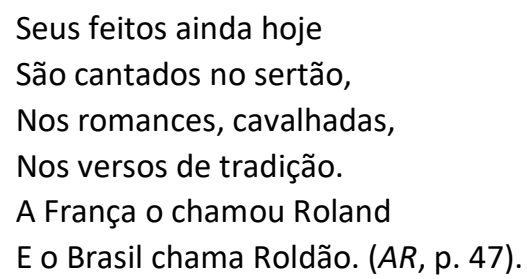

Enquanto os termos-chave romances, cavalhadas e versos ilustram as várias manifestações da presença da matéria carolíngia no Brasil, tanto a tradição quanto Roldão rimam aqui com Sertão, metonímica sertaneja do Nordeste. A dupla filiação, que fecha esse cordel, do sobrinho de Carlos Magno a dois países e a duas línguas é, por sua vez, a afirmação final de que a tradição épica medieval é agora parte integrante não só da herança francesa, mas também da brasileira: “Carlos Magno é sertanejo" 59 .

\section{2 “Os Doze Pares de França” de Toquinho e Belchior}

A saudade e o desejo que o épico carolíngio ainda conseguiu despertar no século XX, em um contexto social e histórico muito particular, também podem ser lidos na canção, acima citada, dos compositores Toquinho (Antonio Pecci Filho) e Belchior (Antonio Carlos Belchior ): "Os Doze Pares de França". O título do álbum, Toquinho Cantando - Pequeno Perfil de um Cidadão Comum, é precisamente contemporâneo do cordel de João Lopes Freire, A História de Carlos Magno e os Doze Pares de França, também editado em 1978, data do 1200 o aniversário da batalha de Roncesvales, associada ao imperador Carlos Magno e ao épico medieval: é pura coincidência?

Ao ritmo nordestino de um coco lento (ou de uma ciranda? ${ }^{60}$, ela não necessita porem a presença de Carlos Magno, o qual em alguns cordéis também parece assumir um papel secundário, atrás de seus famosos paladinos, aqui fundidos em um grupo de cavaleiros indistintos que, na ausência do soberano dispensado de aparecer (cf. v. 11 segs.), criam por conta própria o cenário carolíngio, no limiar dessa canção de contornos sonhadores. Um enraizamento duplo é imediatamente perceptível: saindo de Belém, no coração da Amazônia, os Doze Pares são tão originários da França quanto do Brasil, estando sempre associados a um contexto bélico, graças às suas espadas e às suas montarias. Mais do que na matéria

\footnotetext{
${ }^{59}$ Kunz, Martine, "Cordel, criaçon mestiça”, op. cit., p. 28.

${ }^{60}$ Agradecemos ao Sr. Altamiro Belmiro Rocha Neto por essas valiosas sugestões. 
medieval, porém, seu efeito sobre as mulheres é destacado: o épico parece ter se transformado em força erótica e lirismo amoroso, graças às canções alegremente produzidas por esses cavaleiros para impressionar as moças que encontram nos lugares por onde passam (no v. 8 segs., a rejeição do grupo no verso final cria um certo efeito de surpresa), pois graças à inventividade dos Doze Pares não em questões de guerra, mas de amor (v. 16).

Até mesmo os emblemas chaves do cavaleiro sofrem uma modificação substancial em relação às suas conotações tradicionais. As montarias, cuja brancura lunar é onírica, são acompanhadas pela lança, que, em rima dupla, ecoa a França (v. 1 e v. 5), enfatizando sua origem antiga e mítica. Conquanto o anel não faça parte regular do equipamento cavalheiresco medieval, a possível intertextualidade com alguns textos épicos antigos, mas também com um cordel de Severino José61 associa-o à magia, que também envolve as espadas. Retomando a ideia de um brilho particular que emana dessas últimas já na cordel fundador do corpus carolíngio brasileiro, A Batalha de Oliveiros com Ferrabrás ${ }^{62}$, essa luminosidade, mais uma vez, não é um elemento de força guerreira, mas se liga aqui, no lugar oportuno da segunda função, à terceira função indoeuropéia, a qual Georges Dumézil associa à ideia de fertilidade e abundância: as provas são o retorno à materialidade terrestre (v. 14), à produção agrícola (v. 15 ) e finalmente ao amor e à sexualidade (v. 16).

Todavia, a violência não está totalmente ausente da canção - parece apenas ter transportado para o Eu, cuja voz é mais perceptível na estrofe final, o qual acaba por reorientar no enunciador a visão épica dos Doze Pares. Claro está que a admiração que emana do sonho carolíngio é sempre coletiva, como ilustra a retomada da apóstrofe inicial, "cavaleiro" (do verso 6 ao 18), dessa vez acompanhada por um coro feminino, funcionando como refrão. Não obstante, o foco agora se encontra no $E$ u, do qual o coração é removido, como no lirismo medieval tardio. Porém, ao contrário dos principios desse lirismo antigo, não é mais a bemamada nem o Deus do Amor, mas sim o sonho dos Doze Pares de França que move esse Eu para além do Oceano e da noite, atraindo-o à luz do amanhecer. Finalmente, o nascer do sol ilumina literalmente o significado dessa passagem: ao contrário do Brasil à noite, o almejado amanhecer vem agora é do leste, da Europa. A indecisão paira sobre o referente do epíteto "vermelho como romã": seriam os raios matinais do sol? O peito do Eu, por causa do coração arrancado? A verdade é que, em qualquer dos casos, a formulação bate meu peito refere-se à antiga expressão mea culpa. O Eu se identifica sutilmente com um Rolando, mártir dos tempos antigos, o que também explica a escolha particular da orquestração: a alegria do fliscorne (Flügelhorn) é contrastado pelo timbre intrinsecamente elegíaco e linha melódica mais melancólica do corne inglês, o qual lembra o olifante de Roncesvales...

\footnotetext{
${ }^{61}$ Severino José, A Grande Paixão de Carlos Magnos pela Princesa do Anel Encantado, s. d., narra o amor prodigioso de Carlos Magno por sua quarta esposa, prolongado além de sua morte pelo encantamento produzido por um anel mágico.

62 BOF, pág. 5: "Todos eram conhecidos / Pelos Leões das Igreja, / Pois nunca foram à peleja / Que nela fossem vencidos. / Eram por turcos temidos, / Pela Igreja estimados, / Porque, quando estavam armados, / Suas espadas luziam / E os inimigos diziam : / — Esses são endiabrados!".
} 
A censura da época da ditadura militar, que proibia a disseminação dessa música, não se enganou: ainda que a mensagem dessa denúncia seja muito mais sutil do que um simples desencanto ou uma difamação do Brasil em benefício da França ${ }^{63}$, vemos aí uma rejeição do épico na medida em que ele poderia ser interpretado como violência. Entretanto, os autores mantêm o sonho carolíngio, em versão nostálgica, mas também mais democrática e popular, sem a presença do soberano, e conferem ao Eu a silhueta discreta de um mártir: sem ser expressamente nomeada, a ditadura herda o papel tradicional dos Outros pagãos.

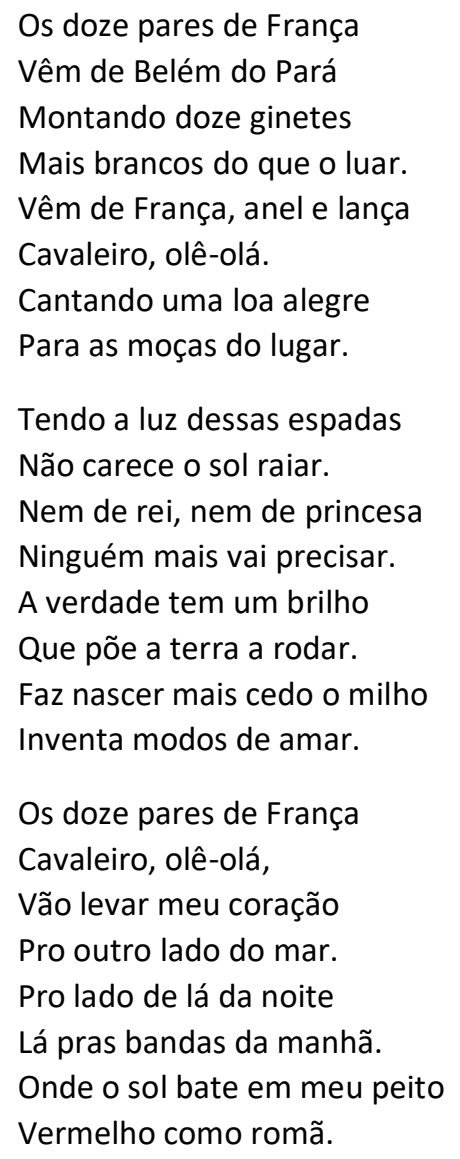

\section{Conclusão}

A exemplo das apropriações da figura mítica de Carlos Magno na Idade Média, seja do lado francês, em canções de gesta, seja do lado alemão, via a canonização ocorrida em 1165, o Brasil abraça plenamente a matéria épica medieval. A herança poética da História do Imperador Carlos Magno não pertence a um grupo em particular: são muitos os reinvestimentos na cultura popular, dos quais tocamos apenas alguns exemplos e gêneros, aos quais poderíamos somar o repente (lirismo popular nordestino) e até mesmo o rap.

\footnotetext{
63 Essa é a censura feita pelas autoridades responsáveis, cf. Site Documentos revelados de Aluízio Palmar, produzido pela editora Gramp, Foz do Iguaçu, https://www.plural.jor.br/documentosrevelados/repressa

o/veto-a-musica-de-belchior-e-exemplo-de-ignorancia-cega-da-censura/[consultado em 16/10/2019]. Os documentos de censura datam de 15 de agosto de 1977, uma coincidência histórica interessante: é o 1199o aniversário da Batalha de Roncesvales. O argumento: "A última 'estrofe' da música em questão transmite uma ideia depreciativa a respeito do viver no Brasil, com uma afirmação de que atualmente seria melhor a vida em outros países."
} 
Ainda que seja uma voz individual e não um grupo que a reivindica, é como arauto de um coletivo que ela assim o faz, de um Nós que se refere no cordel a uma cultura regional, nordestina e além disso, às vezes de forma explícita, à identidade brasileira. No caso da canção de Toquinho e Belchior, expressão mais lírica do nosso corpus, novamente o artista se assemelha a um Rolando: embora a violência do registro épico não pareça mais fazê-lo sonhar, ele é sua vítima, em conformidade com seu papel.

A oposição constantemente atualizada entre cristãos e mouros se presta assim e ainda se prestará a releituras à luz dos conflitos sociais brasileiros, os quais essa oposição poderia sublimar. Para a historiadora Marlyse Meyer, esse maniqueísmo deve ser lido como "uma grande metáfora que possibilitou entender o Brasil”64, e percebemos que mesmo a crítica brasileira atual nem sempre quer se eximir dessa identificação emocional com a matéria medieval, seja ela de França ou da Bretanha, cujo registro épico nos convida a escolher o acampamento não do Outro mas do Nós:

Carlos Magno é como o nosso querido Rei Artur, que com os seus cavaleiros luta a favor da justiça e contra todos aqueles que possam ameaçar a paz de seu Império ${ }^{65}$.

\section{Referências bibliográficas}

ANDRADE, Mário de. Danças dramáticas do Brasil. Belo Horizonte: Itatiaia / INL / Fundação Pró-Memória, 1982.

BASTIDE, Roger. Les religions africaines au Brésil. Contribution à une sociologie des interpénétrations de civivisation. Paris: PUF, 1995 [1960].

BORGES, Francisca Neuma Fechine. "Tradição e contemporaneidade no ciclo carolíngio da literatura de cordel brasileira", in BIANCIOTTO, Gabriel e GALDERISI, Claudio (ed.). L’Épopée romane. Actes du $X^{e}$ Congrès international Rencesvals, Poitiers, 21-27 août 2000. Poitiers: Université de Poitiers, CESCM, 2002 , t. 1.

CANTEL, Raymond. "De Roland à Lampião ou la littérature populaire du Nordeste brésilien", Études, Littératures orales. Paris: 1979.

CASCUDO, Luís da Câmara. "Informação sôbre a História do Imperador Carlos Magno e dos Doze Pares de França", in Cinco livros do povo. João Pessoa: Editora Universitária UFPB, 2e ed., 1979.

CEZAR, Lilian Sagio. "A santa, o mar e o navio : congada e memórias da escravidão no Brasil", Revista De Antropologia, vol. 58, $\mathrm{n}^{\circ} 1$ (2015).

CIRINO, Giovanni. "Atuação missionária no Brasil e na África Centro-Ocidental: uma interpretação dos autos catequéticos", in Dawsey, John; Müller, Regina; Monteiro, Marianna; Hikiji, Rose Satiko (ed.). Antropologia e Performance. São Paulo: Terceiro Nome, 2013, p. 217-234.

CORREIA, João David Pinto. "L'épopée médiévale dans les traditions populaires portugaise et brésilienne", in BIANCIOTTO, Gabriel e GALDERISI, Claudio (ed.). L'Épopée romane. Actes du XV' Congrès international Rencesvals, Poitiers, 21-27 août 2000. Poitiers: Université de Poitiers, CESCM, 2002, t. 1.

${ }^{64}$ Meyer, Marlyse, “Tem Mouro na Costa ou Carlos Magno 'Reis' do Congo”, op. cit., p. 158.

65 Morgado, Georgia Barbosa, "A Permanência do Imaginário Medieval na Literatura de Cordel”, in: Silva, Andréia Cristina Lopes Frazão da; Silva, Leila Rodrigues da (ed.), Atas da IV Semana de Estudos Medievais do Programa de Estudos Medievais da UFRJ, Instituto de Filosofia e Ciências Sociais da UFRJ, de 14 a 18 de Maio de 2001, Rio de Janeiro, Programa de Estudos Medievais, 2001, p. 216-224, a citação está na p. 223. 
DAWSEY, John; MÜLLER, Regina; MONTEIRO, Marianna; HIKIJI, Rose Satiko (éd.). Antropologia e Performance. São Paulo: Terceiro Nome, 2013.

FERREIRA, Jerusa Pires. Cavalaria em cordel. O passo das aguas mortas. São Paulo: Edusp, 2016 [1993].

FERREIRA, João Melchíades. Roldão no Leão de Ouro. São Paulo: Luzeiro, 2007 [antes de 1933].

FILGUEIRA DE ALMEIDA, Dulce. “Corpo, Cultura e Sincretismo: o Ritual da Congada”, Pensar a Prática, vol. 15, № 1 (2012).

FLAVIENSE, Alexandre Gaetano Gomes. Historia do imperador Carlos Magno e dos doze paros de França, traduzida do castelhano, por Jeronymo Moreira de Carvalho... e seguida da de Bernardo del Carpio que venceu em batalha aos doze pares de França. Rio de Janeiro / Paris / Lisboa: Garnier, 1892, disponível na Gallica, https://gallica.bnf.fr/ark :/12148/bpt6k11648284/f5.image [consultado dia 16/10/2019], bem como a versão espanhola de 1780, também online: http://bibliotecavirtualdefensa.es/BVMDefensa/i18n/consulta/registro.cmd?id=1641 [consultado dia 16/10/2019].

FREIRE, João Lopes. A História de Carlos Magno e os doze pares de França. Rio de Janeiro: Barros Filho, [1978].

GOMES DE BARROS, Leandro. A Batalha de Oliveiros com Ferrabrás. São Paulo: Luzeiro, 2012 [1908 ( ?)].

GOMES DE BARROS, Leandro. A Prisão de Oliveiros e seus Companheros [continuação do precedente]. São Paulo: Luzeiro, 2012 [1908 (?)].

GOYET, Florence. Penser sans concepts : fonction de l'épopée guerrière. Paris: Champion, 2006.

GRUZINSKI, Serge. La Pensée métisse. Paris: Fayard, 2012.

HAURÉLIO, Marco. Aventuras de Roldão o Paladino de França, publicação prevista em 2022.

KUNZ, Martine. "Cordel, criaçon mestiça”, Cultura critica, $n^{\circ} 6$ (2008).

LANGENBRUCH, Beate. "Charlemagne le Brésilien: la figure de l'empereur construite par le cordel du Nordeste", in KULLMANN, Dorothea. Oltre la mer salee. XXIe Congrès International de la Société Rencesvals, 13-17 août 2018. Toronto: Pontifical Institute of Mediaeval Studies, a ser publicado em 2022.

LANGENBRUCH, Beate. Images de l'Allemagne dans quelques chansons de geste des douzième et treizième siècles. Tese de doutorado defendida na Universidade de Rouen, Orient. Jean Maurice, 2007.

LANGENBRUCH, Beate. "La Frontière : défi et richesse pour les recherches sur l'épique médiéval", in LODÉN, Sofia e OBRY, Vanessa (ed.). L'expérience des frontières et les littératures de l'Europe médiévale. Paris: Champion, 2019.

LANGENBRUCH, Beate. "Pérégrinations transeuropéennes et transatlantiques de la matière épique médiévale : enjeux de traduction, entre la France et le Brésil", in LAUTEL-RIBSTEIN, Florence e BUHOT DE LAUNAY, Marc-André (ed.). Archéologies de la traduction. Paris: Classiques Garnier (Translatio), 2020, p. 195-213.

LE PERSON, Marc (ed). Le Rayonnement de Fierabras dans la littérature européenne, Actes du Colloque international des 6 et 7 décembre 2002. Lyon: APRIME, “C.E.D.I.C, 21", 2003.

LIMA, Stélio Torquato. A Canção do Rolando em cordel. Mossoró: Queima-Bucha, s. d. [2009].

MANDACH, André de. Naissance et développement de la chanson de geste en Europe, V. La Geste de Fierabras. Le jeu du réel et de l'invraisemblable. Genève: Droz, 1987.

MELO, Veríssimo de. "Literatura de Cordel. Visao historica e aspectos principais", Literatura de cordel. Antologia. Fortaleza: Banco do Nordeste do Brasil, 1994. 
MEYER, Marlyse. Caminhos do imaginário no Brasil. São Paulo: Edusp, 1993.

MONTERO, Luis Humberto Olera. “La 'Historia de Carlo Magno' en el desarrollo del romancero a la décima espinela", Revista Chilena de Literatura, $n^{\circ} 78$ (2011), online: https://web.archive.org/web/20131231074431/http://revistaliteratura.uchile.cl/index.php/RCL/article/vie wArticle/11021/11437 [consultado dia 16/10/2019].

MONTEIRO, Duglas Teixeira. Os Errantes do Novo Século. São Paulo: Duas Cidades, 1974.

MORGADO, Georgia Barbosa. "A Permanência do Imaginário Medieval na Literatura de Cordel", in SILVA, Andréia Cristina Lopes Frazão da; SILVA, Leila Rodrigues da (ed.), Atas da IV Semana de Estudos Medievais do Programa de Estudos Medievais da UFRJ, Instituto de Filosofia e Ciências Sociais da UFRJ, de 14 a 18 de Maio de 2001. Rio de Janeiro: Programa de Estudos Medievais, 2001, p. 216-224.

QUEIROZ, Maurício Vinhas de. Messianismo e conflito social (A Guerra sertaneja do Contestado 1912-1916. São Paulo: Ática, 1981.

SAAVEDRA, Yolando Pino. "La Historia de Carlomagno y de los Doce Pares de Francia en Chile", Folklore Américas, $n^{\circ} 26$ (1966).

SAILLANT, Francine e ARAUJO, Ana Lucia. "L'esclavage au Brésil : le travail du mouvement noir", Ethnologie française, vol. $37, n^{\circ} 3$ (2007).

[SAMPAIO, Marcos alias MOURA, Moisés Matias de]. A Morte dos 12 pares de França. Juazeiro [do Norte, Ceará]: José Bernardo da Silva, 1961.

SANTOS, Idelette Muzart Fonseca dos. La Littérature de cordel au Brésil : mémoire des voix, grenier d'histoires. Paris: L'Harmattan, 1997.

SEVERINO JOSÉ [alias SANTOS, Zacarias José dos]. A Grande Paixão de Carlos Magnos pela Princesa do Anel Encantado. s. I., s. d. [1977].

SILVA, Antonio Eugênio da. O Cavaleiro Roldão. Campina Grande: dos Santos, s. d. [antes de 1942].

SILVA, Damásio Paulo da. Historia de Carlos Magnos [E Os] 12 Pares com Malaco Rei de Fez. Juazeiro do Norte: José Bernardo da Silva, s. d. [antes de 1949].

SILVA, Severino Borges da. O Guerreiro Bernardo de Cárpio. Exímio vencedor dos doze pares de França. Recife: João José da Silva, 1996 [anos 1950 o 1960 ?].

SLATER, Candice. Stories on a string: The Brazilian Literatura de Cordel. Berkeley: University of California Press, 1982.

SUARD, François (ed.), Aspremont. Chanson de geste du XIle siècle. Paris: Champion, 2008. 